\title{
Hondroplastic Efficiency of Calcified Bone Matrix Produced by Original Technology
}

\author{
Yuri M. Iryanov, $\mathrm{PhD}, \mathrm{ScD}^{1^{*}}$; Nikolay A. Kiryanov, $\mathrm{PhD}, \mathrm{ScD}^{2}$ \\ ${ }^{1}$ Russian Ilizarov Scientific Center Restorative Traumatology and Orthopedics, Kurgan, Russia \\ ${ }^{2}$ Izhevsk State Medical Academy, Izhevsk, Russia
}

\begin{abstract}
The purpose of our research was to study the chondroplastic efficiency of the bone matrix obtained by the original technology, while restoring the defect of cartilage of the knee joint.

Methods: In 40 adult Wistar male rats, marginal defects were modeled on the surface of the distal end of the femur. The animals of the experimental group were implanted with bone matrix into the damage zone. The material was examined by light microscopy, transmission and scanning electron microscopy, and X-ray electron probe microanalysis.

Results: It was established that bone matrix did not cause immune rejection reaction and has prolonged activated reparative chondrogenesis. In the area of articular cartilage damage, a regenerate was formed, acquiring cellular and histochemical specificity of the hyaline cartilaginous tissue. The properties of the chondroinductor to the bone matrix were ensured by localized growth factors and bone morphogenetic proteins released during osteoclastic resorption.

Conclusion: The use of bone matrix as a stimulant of chondrogenesis is theoretically justified and has a good prospect in the treatment of articular cartilage damage and diseases. (International Journal of Biomedicine. 2018;8(2):142-146.)
\end{abstract}

Key Words: articular cartilage $\bullet$ bone matrix $\bullet$ implantation $\bullet$ chondrogenesis

\section{Introduction}

Damage or loss of articular cartilage due to congenital anomalies, degenerative diseases of joints, or injuries has a negative impact on the quality of life of victims in all age groups and is an expensive medical problem. The main methods of plastic surgery for cartilage defects are currently: stimulation of reparative chondrogenesis by perforation of the subchondral bone at the bottom of the defect, replacement of the damage area by structural auto- and allografts, use of cellular technologies. ${ }^{(1)}$ However, with osteoperforation, a fibrous cartilage is formed in the defect area, which, in its biomechanical characteristics, is significantly inferior to hyaline cartilage. The use of autografts is associated with an additional traumatic effect and a post-traumatic inflammatory process. This increases the blood loss and the duration of the operation. This method is limited by the inability to take

*Corresponding author: Prof. Yuri M. Iryanov, PhD, ScD; Laboratory of Morphology, Russian Ilizarov Scientific Center Restorative Traumatology and Orthopedics, Kurgan, the Russian Federation.E-mail: irianov@mail.ru the necessary amount of autogenous material, especially in children whose donor zones are small, and tissue capture can lead to disruption of local growth. ${ }^{(2)}$ When allografts are used, cadaveric material, in which there are no viable chondrogenic cells, is also used. This raises ethical and moral problems. There is a potential danger of transmission of various diseases and infection to the recipient, including prion agents, hepatitis $\mathrm{C}$ and $\mathrm{B}$ viruses, and HIV infection. Histone compatibility and a number of serious immune complications develop, which are often accompanied by suppuration in the postoperative period and rejection of the transplant. ${ }^{(3)}$ The use of methods of cellular technology and tissue bioengineering is hampered by low proliferative activity of chondroblasts, the development of aseptic inflammation (in which a significant part of implanted cells die or lose its phenotype), and the disruption of the trophic of regenerate. ${ }^{(1,4)}$ The use of polypotent bone marrow stromal cells, which under the influence of the microenvironment of the zone of the cartilaginous defect are able to differentiate in the direction of the chondrocytes, ${ }^{(5)}$ is accompanied by the spread of cells across all the joint cavity. Chaotic disorderly cytoarchitectonics of the regenerate is formed, as are dense scars, adhesions, and stiffness of the 
joint. Despite the numerous methods developed, none of them lead to a full-fledged organ-specific recovery of the articular hyaline cartilage. ${ }^{(6)}$ This indicates the urgency of the problem and the timeliness of the present study.

The purpose of our research was to study the chondroplastic efficiency of the bone matrix obtained by the original technology, while restoring the defect of cartilage of the knee joint.

\section{Materials and Methods}

In our study, we used 40 mature Wistar rats with a body weight of $340-390 \mathrm{~g}$. The animals were divided into two groups: experimental and control with 20 individuals in each group. All manipulations were carried out in accordance with RF Order No. 708n of 23.08.2010 "On the Approval of the Rules of Laboratory Practice", those of the "European Convention for the Protection of Animals used for Experimental and other Scientific Purposes" and approved by the National Ethics Committee Protocol No. 3 (16) 02/02/2018).

\section{Description of the intervention}

In rats under operating conditions using general anesthesia (romomet $8 \mathrm{mg}$ and zolletil $4 \mathrm{mg}$ per $1000 \mathrm{~g}$ of body weight intramuscularly) on the patellar surface of the distal end of the right femur a dental boron was used to simulate a blind final defect with a diameter of $2.5-3 \mathrm{~mm}$ before penetrating the subchondral bone. In animals of the experimental group, a sterile, granular, allogeneic bone matrix with a mass of 2-3 mg was introduced into the defect region, obtained from the tubular bones of rats according to the original technology. ${ }^{(7)}$ The technological process did not require an increase in thermal, acid and alkali effect, which reduced the risk of denaturation of the protein-chondroinductor. In the control group, no additional manipulation was performed and the defect zone was left to heal under the blood clot. At 7, 15, 30 and 60 days after the operation, the animals were withdrawn from the experiment (5 animals were used for each time point).

\section{Methods of research and registration of outcomes}

The operated femurs were fixed in a solution of paraformaldehyde and glutaraldehyde and poured over with paraffin (after decalcification) and araldite (without decalcification). Paraffin sections were stained with hematoxylin-eosin and picrofuxin according to Van Gieson and examined in the AxioScope. An A1 light microscope and an AxioCam digital camera (Carl Zeiss MicroImaging $\mathrm{GmbH}$, Germany) were used. To reveal histochemical markers of hyaline cartilage (non-sulfated glycosaminoglycans (NSGAG) and sulfated glycosaminoglycans (SGAG)), the sections were stained with alcian blue at $\mathrm{pH} 2.5$ and 1.0. The content of glycosaminoglycans was determined in conventional units (CU). For this purpose, the concentration of the alcian blue dye in the sections was determined by the content of copper included in its composition (formula Alcian blue $8 \mathrm{GS}: \mathrm{C}_{44} \mathrm{H}_{42} \mathrm{Cl}_{2} \mathrm{CuN}_{12} \mathrm{~S}_{2}$ ). An energy dispersive $\mathrm{X}$-ray spectrometer (X-ray electron probe microanalyzer) of INCA-200 Energy (Oxford Instruments, Great Britain) ${ }^{(8)}$ was used. Araldite blocks were treated in a $2 \%$ solution of sodium ethioate (saturated solution of $\mathrm{NAOH}$ in absolute ethanol) to remove the araldite, sprayed with a platinum-palladium alloy (1: 3 ratio) in an IB-6 ionic vacuum sprayer (Eico, Japan) and studied in a scanning electron microscope JSM-840 (Jeol, Japan) in secondary electrons with an accelerating voltage of $20 \mathrm{kV}$. Ultrathin sections 50-60 nm thick were obtained with the ultramicrotome LKB-8800 (LKB, Sweden). Ultrathin sections were stained with a $1 \%$ aqueous solution of uranyl acetate and lead citrate by Reynolds and studied using a JEM2010 transmission electron microscope (Jeol, Japan) at an accelerating voltage of $80 \mathrm{kV}$.

Statistical analysis was performed using StatSoft Statistica v6.0. The mean (M) and standard error of the mean (SEM) were calculated. The Mann-Whitney (U Test) was used to compare the differences between the two independent groups. A probability value of $P<0.05$ was considered statistically significant.

\section{Results}

The implantable bone matrix granules had a size of 50$200 \mu \mathrm{m}$ in diameter and an ordered, highly porous structure (Figure 1). The pores corresponded to the sites of localization of osteocyte lacunae and bone ducts, from which the cells and other non-mineralized organic components of the bone matrix were removed. Calcification of granules was uniform throughout their volume (Figure 1b). The content of chemical macro elements in granules is presented in Table 1.

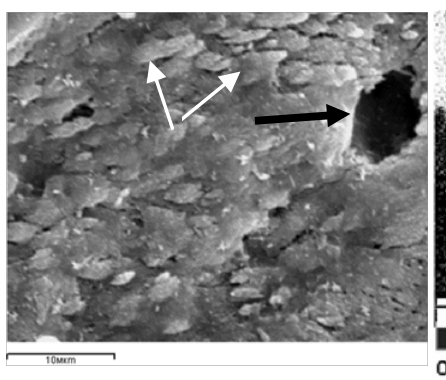

a

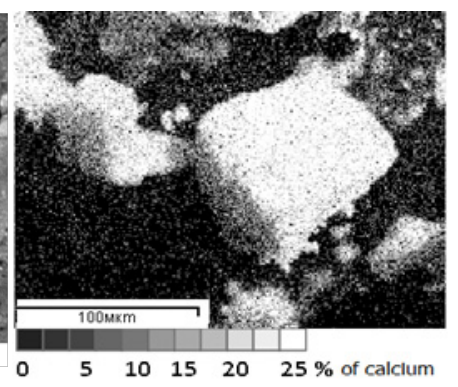

b
Fig. 1. Stereo-ultrastructure (a) and calcium distribution (b) in the bone matrix granules: a - scanning electron microscopy (black arrow - osteocyte lacuna, white arrow - calcified matrix vesicles accumulating $B M P)$, magnification $\times 3000 ; b-X$-ray electron probe microanalysis map, an image in the characteristic $X$-ray emission of calcium atoms, magnification $\times 400$.

Table 1.

The chemical composition of implantable bone matrix granules (M \pm SEM, \%)

Chemical Sodium Magnesium Phosphorus Sulfur Calcium \begin{tabular}{l|l|l|l|l|l|l} 
elements & $0.44 \pm 0.02$ & $0.35 \pm 0.01$ & $13.59 \pm 0.65$ & $0.28 \pm 0.01$ & $25.76 \pm 1.33$ \\
\hline
\end{tabular}

Seven days after the operation, the joint capsule was hyperemic and edematous in the control and experimental groups. The cartilage coating acquired a matte shade. In the zone of damage, signs of inflammatory reaction and alterativedestructive transformations affecting all components of metaepiphysis were revealed. Foci of organized hematoma, infiltrated with fibrin clots, poorly differentiated cellular 
elements, neutrophilic granulocytes, macrophages, mast cells, extravasal erythrocytes and lymphocytes, as well as leukocyte-necrotic masses containing lysed cells and fibrin strata, were detected. The articular cartilage was scarified. The defect area was partially replaced by granulation and poorly differentiated loose connective tissue with signs of edema and a few vessels. Statistically significant changes in the content in the joint cartilage damage zone of the NSAH and SGAH were not detected in either the control or experimental groups at this stage of the experiment (Table 2).

\section{Table 2.}

The content of NSGAG and SGAG in the knee cartilage damage zone in the control group of animals (control) and in the implantation of bone matrix pellets (experiment) $(M \pm S E M, C U)$

\begin{tabular}{c|c|c|c|c}
\hline \multirow{2}{*}{$\begin{array}{c}\text { Term of } \\
\text { experiment, } \\
\text { day }\end{array}$} & \multicolumn{2}{|c|}{ Control } & \multicolumn{2}{c}{ Experiment } \\
\cline { 2 - 5 } & $\begin{array}{c}\text { NSGAG } \\
(\mathrm{n}=5)\end{array}$ & $\begin{array}{c}\text { SGAG } \\
(\mathrm{n}=5)\end{array}$ & $\begin{array}{c}\text { NSGAG } \\
(\mathrm{n}=5)\end{array}$ & $\begin{array}{c}\text { SGAG } \\
(\mathrm{n}=5)\end{array}$ \\
\hline 7 & $0.18 \pm 0.01$ & $0.11 \pm 0.01$ & $0.20 \pm 0.01$ & $0.12 \pm 0.01$ \\
15 & $0.19 \pm 0.01$ & $0.12 \pm 0.01$ & $0.49 \pm 0.01^{*}$ & $0.26 \pm 0.01^{*}$ \\
30 & $0.21 \pm 0.01$ & $0.16 \pm 0.01$ & $0.56 \pm 0.02^{*}$ & $0.54 \pm 0.01^{*}$ \\
60 & $0.22 \pm 0.01$ & $0.24 \pm 0.01$ & $0.59 \pm 0.03^{*}$ & $0.70 \pm 0.01^{*}$ \\
\hline
\end{tabular}

Fifteen days after the operation, numerous leukocytes, collagen fiber bundles, granulation tissue and a significant number of dilated and blood-filled vessels were detected in the central group of the defect in the central zone of the defect. In the experimental group, the cell-fibrous elements of inflammation were not detected. Implanted bone matrix granules were presented on sections in the form of cystic cavities filled with basophilic (when stained with hematoxylin-eosin) and osmiophilic (on ultrathin sections) substance. Collagen fibers were not detected in them. On the surface and inside, macrophages and functionally active osteoclasts with numerous nuclei and brush border were localized (Figure 2).

Extended sinusoids were surrounded by proliferating perivascular cells. In the defect, there were no hemorrhages, foci of perifocal inflammation, active proliferation of fibroblasts, or intense neoangiogenesis. On the surface of the granules were layers of chondrogenic cells at various stages of differentiation. The area of the articular cartilage defect was partially filled with newly formed hyaline cartilage, the intercellular substance of which contained predominantly NSAGG. The edges of the defect merged with the edges of the "parent" articular cartilage, where cell nests with isogenic groups of chondrocytes were detected.

* $P<0.01$ - intergroup differences

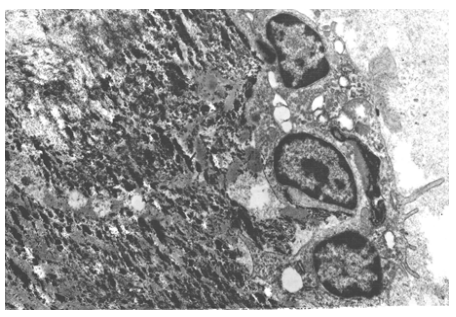

a

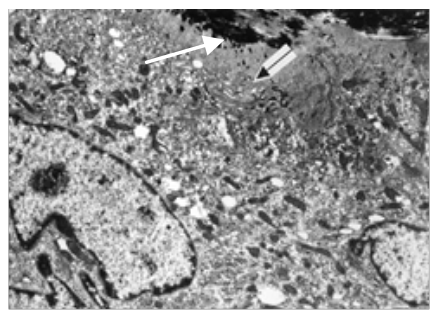

$\mathrm{b}$

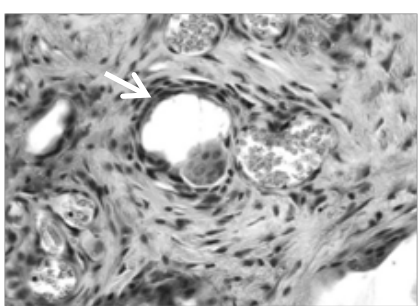

Fig. 2. Osteoclastic resorption of bone matrix granules in the defect of cartilage of the knee joint: $a-15$ days, $b-30$ days, $c$ - 60 days after the operation; $a, b$ - transmission electron microscopy of ultrathin sections (white arrows - bone matrix granules, black arrow - brush border of osteoclast), magnification $\times 8000$; c - light microscopy of the paraffin section, staining with $H \& E$. Lens 40, eyepiece 10.

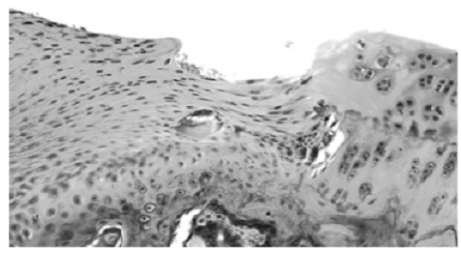

a

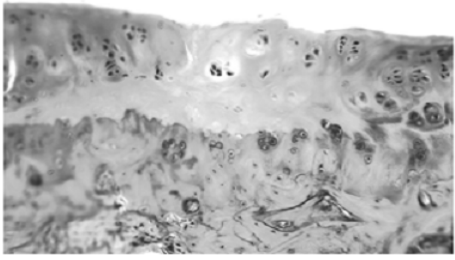

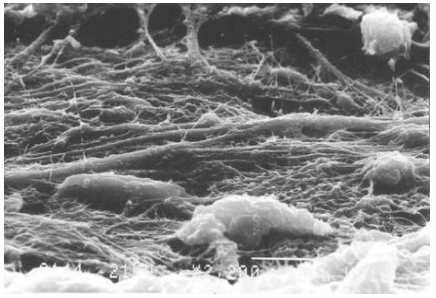

b

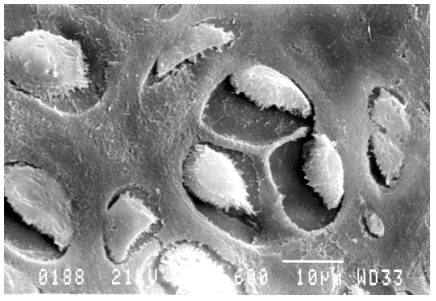

$\mathrm{b}$

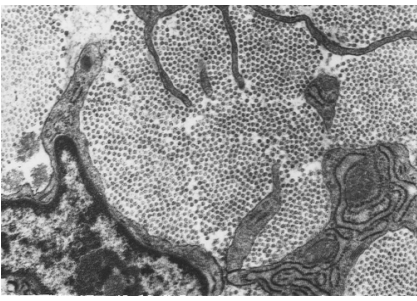

$\mathrm{C}$

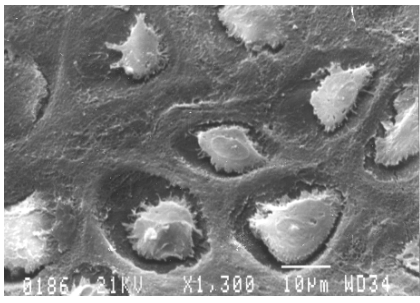

Fig. 3. The area of the defect in the cartilage of the knee joint is 60 days after the operation: $a, b, c$ - a control group (the defect is replaced by a fibrous connective tissue); $d, e, f$-experimental group of animals (defect is filled with newly formed hyaline cartilage); $a, d$-paraffin sections. Staining with H\&E. Lens 10, eyepiece 10; $b, e, f$-scanning electron microscopy, magnification $\times 1300$; $c$ - transmission electron microscopy, magnification $\times 5000$. 
The presence of the latter testified to the proliferative activity of a part of the chondroblasts, which are one of the cellular sources of the cartilaginous tissue that fills the defect. The second source of chondrocytes is cells located around implanted granules. The concentration of glycosaminoglycans in the defect area in the experiment was more than 2 times higher than the control values (Table 2).

At 30 and 60 days after the operation, in the control group a considerable volume of the defect zone was filled with a loose and dense connective tissue (Figures 3a, 3b, 3c). Newly formed cartilaginous tissue in the form of isogenic groups of chondrocytes was detected only in small areas near the edges of the defect. In the experimental group, the articular cartilage defect was almost completely filled with the newly formed hyaline cartilage with a smooth surface (Figures 3d, 3d, 3e), which grew rounded from the edges of the defect, where the formed isogenic groups of cells were located. The surface of the newly formed hyaline cartilage acquired a shine characteristic of the joint cartilage of intact animals. The cellular population of the cartilaginous regenerate was represented mainly by proliferating chondroblasts; its structure did not yet have a specificity characteristic of articular cartilage. The content of non-sulphated and sulfated forms of glycosaminoglycans 30 days after the operation in the defect in the experiment was more than 2 times higher than the control indices, but did not differ significantly between each other. After 60 days the sulfated forms of glycosaminoglycans prevailed, which indicated a higher degree of maturity of the newly formed cartilaginous tissue (Table 2), reaching the degree of maturity peculiar to articular cartilage of intact animals.

\section{Discussion}

It is known that mature hyaline cartilage has an insignificant restoration potential due to low cell density and low mitotic activity of chondrocytes. Large defects of articular cartilage are replaced by biomechanically defective fibrous cartilage with subsequent development of osteoarthritis..$^{(9)}$ The advent of tissue engineering techniques has provided alternative options for treating such patients by using cellular therapy in combination with synthetic extracellular matrix substitutes and biologically active factors for the functional replacement of articular hyaline cartilage. ${ }^{(10)}$ This study showed that the bone matrix granules, when implanted into the articular cartilage defect zone, have a pronounced chondromodulatory effect, prolonged by activating reparative chondrogenesis. In the area of damage to the articular cartilage in the early period, a regenerate is formed, acquiring the cellular specificity of the hyaline cartilaginous tissue. A holistic cartilage covering is formed and the outline of the articular surface is gradually leveled, which leads to a complete or partial restoration of the functional activity of the joint. The properties of the chondroinductor implantation granules of bone matrix can provide localized growth factors and bone morphogenetic proteins (BMP), which are released during osteoclastic resorption. ${ }^{(11)}$ According to the results of modern studies, BMPs are the most important factors in bone and cartilage regeneration. ${ }^{(12)}$ Experimental studies and extensive clinical application have demonstrated the effectiveness of BMP as an active stimulant of osteogenesis and chondrogenesis, in its regenerative potential of equal or superior autologous material. ${ }^{(13,14)}$ BMPs act on the receptors of the cell membrane and play a significant role in regulating the growth, differentiation and apoptosis of various cell types including osteoblasts, chondroblasts, and nerve and epithelial cells. $^{(15)}$ To date, 20 types of BMP have been identified. The most fully studied for the regeneration of bone and cartilage are BMP-2 and BMP-7, but there are reports of active participation in osteogenesis and chondrogenesis and other BMP species. ${ }^{(16)}$ Two technological methods for obtaining BMPs are known: biochemical extraction from demineralized bone matrix and synthesis using genetic engineering (rhBMP). ${ }^{(17,18)}$ Both methods are very laborious, expensive and require the use of acids and alkalis. The technological process used to produce the implantation biomaterial does not require the use of an elevated thermal and acid-base effect, which reduces the risk of denaturation of the protein-chondroinductor.

\section{Conclusion}

Our research has shown that the use of granulated bone matrix obtained by the original technology without thermal, acid and alkaline treatment as a stimulator of chondrogenesis and corrector of destructive disorders in the cartilaginous tissue with damage to the articular cartilage is theoretically justified and can have a good prospect in clinical practice in the treatment of injuries and articular cartilage diseases.

\section{Conflict of interest}

The authors declare that they have no conflicts of interest to disclose.

\section{References}

1. Gerasimov SA, Tenilin NA, Korytkin AA, Zykin AA. [Surgical treatment of localized injuries to articular surface: the current state of the issue]. Polytrauma. 2016;1:63-69. [Article in Russian].

2. Lee SH, Yoo CJ, Lee U, Park ChW, Lee SG, Kim_WK. Resorption of Autogenous Bone Graft in Cranioplasty: Resorption and Reintegration Failure. Korean J Neurotrauma. 2014;10(1):10-14. doi: 10.13004/kjnt.2014.10.1.10.

3. Singh R, Singh D, Singh A. Radiation sterilization of tissue allografts: A review. World J Radiol. 2016; 8(4):355-69. doi: $10.4329 /$ wjr.v8.i4.355.

4. Filardo G, Kon E, Roffi A, Di Martino A, Marcacci M. Scaffold-based repair for cartilage healing: a systematic review and technical note. Arthroscopy. 2013;29(1):174-86. doi: 10.1016/j.arthro.2012.05.891.

5. Hustedt JW, Jegede KA, Badrinath R, Bohl DD, Blizzard DJ, Grauer JN. Optimal aspiration volume of vertebral bone marrow for use in spinal fusion. Spine J. 2013;13(10):121722. doi:10.1016/j.spinee.2013.07.435.

6. Johnstone B, Alini M, Cucchiarini M, Dodge GR, Eglin $\mathrm{D}$, Guilak F, et al. Tissue engineering for articular cartilage repair--the state of the art. Eur Cell Mater. 2013;25:248-67.

7. Iryanov YuM, Iryanova TYu. Biomaterial for the repair 
of bone defects and the way it is produced. RF Pat 2478394 (Russian Ilizarov Scientific Center «Restorative Traumatology and Orthopedics») Bul. 2013;10:1-2 [in Russian].

8. Irianov YuM, Irianova TYu. [Roentgenologic electron probe microanalysis in quantitative histochemistry]. Morphological Newsletter. 2010;3:77-79.[Article in Russian].

9. Makris EA, Gomoll AH, Malizos KN, Hu JC, Athanasiou KA. Repair and tissue engineering techniques for articular cartilage. Nat Rev Rheumatol. 2015;11(1):21-34. doi: 10.1038/ nrrheum.2014.157.

10. Saintigny Y, Cruet-Hennequart S, Hamdi DH, Chevalier F, Lefaix JL Impact of therapeutic irradiation on healthy articular cartilage. Radiat Res. 2015;183(2):135-46. doi: org/10.1667/ RR13928.1.

11. Camp CL, Stuart MJ, Krych, AJ. Current concepts of articular cartilage restoration techniques in the knee. Sports Health. 2014;6(3):265-73. doi: 10.1177/1941738113508917. 12. Caldwell KL, Wang J. Cell-Based articular cartilage repair: the link between development and regeneration. Osteoarthritis Cartilage. 2015; 23(3):351-62. doi: 10.1016/j. joca.2014.11.004.
13. Mardones R, Jofré CM, Minguell JJ. Cell Therapy and Tissue Engineering Approaches for Cartilage Repair and/or Regeneration. Int J Stem Cells. 2015;8(1):48-53. doi: 10.15283/ ijsc.2015.8.1.48.

14. Kaur S, Grover V, Kaur H, Malhotra R. Evaluation of bone morphogenic proteins in periodontal practice. Indian $\mathrm{J}$ Dent. 2016;7(1):28-37. doi: 10.4103/0975-962X.179379.

15. Jain AP, Pundir S, Sharma A. Bone morphogenetic proteins: The anomalous molecules. J Indian Soc Periodontol. 2013;17:583-6. doi: 10.4103/0972-124X.119275.

16. Oryan A, Kamali A, Moshiri A, Baghaban Eslaminejad M. Role of Mesenchymal Stem Cells in Bone Regenerative Medicine: What Is the Evidence? Cells Tissues Organs. 2017;204(2):59-83. doi: org/10.1159/000469704.

17. Scarfî S. Use of bone morphogenetic proteins in mesenchymal stem cell stimulation of cartilage and bone repair. World J Stem Cells. 2016;8(1):1-12. doi: 10.4252/wjsc. v8.i1.1.

18. Cecchia S, Benneta SJ, Arora M. Bone morphogenetic protein-7: Review of signalling and efficacy in fracture healing. Journal of Orthopaedic Translation. 2016;4:28-34. 